\title{
Questões TeóRico-Descritivas em \\ Sociolingüística e em Sociolingüística Aplicada E \\ uma Proposta de Agenda de Trabalho ${ }^{1}$
}

(Theoretical and Descriptive Issues in Sociolinguistics and in

Applied Sociolinguistics and a Project for an Agenda)

\author{
Maria Cecília de Magalhães MoluiCA \\ (Universidade Federal do Rio de Janeiro-CNPq) \\ Cláudia Nívia RonCARATI \\ (Universidade Federal Fluminense-CNPq)
}

\begin{abstract}
This article attempts a comprehensive review of the basic assumptions that define Brazilian Sociolinguistics approach and offers a set of basic questions guiding the research program to which the field is committed. It also sketches the relevant results through pointers and its implications for applied Sociolinguistics.
\end{abstract}

KEY-WORDs: Developments and issues in Brazilian Sociolinguistics; Goals; Recent trends; Perspectives; Applications.

REsumo: Este artigo oferece uma visäo das questōes cruciais que demarcam o perfil da Sociolingüistica brasileira e delineia uma agenda de pesquisa para a área. Discute os principais resultados através das metas alcançadas e a serem atingidas e avalia as especificidades da Sociolingüistica Aplicada.

PaLAVRAS-CHAVE: Desenvolvimentos e questöes da Sociolingüística no Brasil; Metas; Tendências recentes; Perspectivas; Aplicaçōes.

\footnotetext{
${ }^{1}$ Este texto é resultante de diretrizes básicas traçadas no âmbito do GT de Sociolingüística, durante o XV Encontro Nacional da ANPOLL, realizado em julho de 2000 na Universidade Federal Fluminense. Pressupóe que os especialistas da área tenham conhecimento da bibliografia nacional e internacional mais representativa. Por isso, as referências bibliográficas aqui mencionadas não são extensivas, mas remetem a estudos que resenham ampla gama da produção sociolingüística no Brasil.
} 


\section{Introdução}

A Sociolingüística no Brasil, área de pesquisa efetivamente consolidada, enfatizou a pesquisa sincrônica em suas descriçōes da fala sobre o português no território nacional a partir da década de 70 até o final do século $\mathrm{XX}$, em paralelo à produção internacional da área que se encontra sintetizada em Labov (1994 e 2000). Diagnósticos de variação estável e de mudança em progresso sempre estiveram em pauta, o que não impediu que a dimensão diacrônica estivesse também no bojo das preocupaçōes da área. Nesse sentido, busca-se priorizar a investigação de fenômenos de variação sincrônica em suas dimensões de mudança e estabilidade e formular hipóteses sobre o que esses dois aspectos têm em comum.

A maioria dos pesquisadores congrega-se em Projetos Integrados, formando pólos de atuação que permitem estabelecer uma rede complementar de resultados, referendando-os ou contestando-os. Ao adotar perspectivas diferentemente priorizadas, em grupo ou isoladamente, os estudiosos recobrem um painel de conhecimentos sobre as dimensões geodialetal, sócio-estratificada, histórico-social e discursivo-cultural.

\section{Delimitação de metas}

Um dos objetivos de relevância da Sociolingüística consiste em fornecer subsídios metateóricos para construir um modelo de mudança mais definido e adequado. Perguntas pontuais têm sido incluídas na agenda acadêmica da área, com a finalidade de compreender melhor os dois níveis em que a mudança afeta seja o indivíduo seja a comunidade. Que processos de variação podem levar à mudança? Por que caminhos a mudança se dá? As mudanças são direcionadas por princípios? Que princípios governam essa direcionalidade? Como as mudanças se encaixam no sistema? De que modo as variáveis sociais atuam em casos de variação estável e de mudança em progresso? Qual a participação do léxico e do nível discursivopragmático em fenômenos de variação e mudança? Como se conjugam índices diacrônicos e sincrônicos em fenômenos de mudança?

O conjunto de pesquisas voltadas para essas questôes constitui a produção científica de base acerca da natureza da mudança (cf. Lemle \& Naro, 1977; Bortoni, 1984; Tarallo,1989; Bisol, 1991; Mollica, 1992; Oliveira 
e Silva \& Scherre,1996; Hora, 1997; Hora \& Christiano, 1999) e do funcionamento da língua em uso (cf. Macedo \& Roncarati \& Mollica, 1996), bem como acerca da sua aquisição (Roncarati \& Mollica, 1997). Busca-se definir o imbricamento entre categorias, mecanismos e princípios funcionais de estruturas evolutivas e/ou em evolução e o seu grau de afetamento na eficácia comunicativa do sistema, cujas forças equilibradoras atuam harmonicamente ao promover economia, generalização, associação, simplificação e simbolização. Paralelamente, busca-se lidar com princípios como isomorfismo, motivação e instauração da arbitrariedade lingüística. Investigam-se, também, questóes como transparência e opacidade, graus de informatividade, refinamento de status informacional e interação entre processos cognitivos e embalagem lingüística .

Pode-se afirmar que já exibimos expressivo acervo de pesquisas dessa natureza sobre a fala e a escrita, com o fito de: (a) analisar a variação, aquisição e mudança lingüística, abrangendo fenômenos morfossintáticos, fonológicos e discursivo-pragmáticos; (b) descrever processos de mudança que evidenciam e favorecem a gramaticalização de itens e construções lingüísticas; (c) investigar atitudes e crenças lingüísticas implicadas na variação lingüística e (d) identificar estratégias argumentativas envolvidas no texto escrito e suas marcas lingüísticas.

Os trabalhos na área focalizam ora os indivíduos (os falantes) ora o sistema da língua. As pesquisas podem revelar também que, no início, as mudanças se dão com condicionamentos estruturais ou sociais fracos, pouco perceptíveis. No decorrer do tempo, no entanto, no espaço de algumas gerações (a depender da variável), as variações que tendem a câmbio adquirem maior grau de contextualização e exibem condicionamentos mais evidentes conseqüentemente (Paiva \& Scherre, 1999).

Grande parte das pesquisas contribui para o entendimento mais aprofundado sobre processos de mudança, lançando mão de dados históricos e de dados de diferentes estágios da língua (cf. Mattos e Silva, 1996; Mollica, 1995). Em alguns trabalhos, a questão da mudança no português explica-se pela diferença de input de uma regra historicamente mensurada. Um modelo de mudança deve, assim, dar conta de diferenças em pesos relativos, atestadas em estágios do português, considerando restrições estruturais recorrentes. Ademais, estudos sobre mudança propiciam a discussão em torno de hipóteses relacionadas à alegada crioulização no português do Brasil (Couto, 1996; Tarallo \& Alkmim, 1987). 
Ao examinar causas externas da variação e da mudança lingüística, um modelo satisfatório deve incorporar a análise do perfil social dos falantes de uma dada comunidade de fala. Tradicionalmente, variáveis sociais independentes como idade, sexo e classe social são parâmetros pertinentes, seja para estudar a heterogeneidade lingüística, seja para indicar o dinamismo das mudanças em tempo aparente. Esses parâmetros extralingüísticos dividem a sociedade em grupos fixos, estabelecem correlações diretas entre uso de variantes e estratificação social e buscam identificar o locus da mudança no indivíduo em determinado ponto da estrutura social. Daí a coexistência de grupos inovadores e conservadores em uma relação dinâmica que pode apontar os caminhos da língua.

O percurso de uma mudança pode não se apresentar de forma transparente. No processo de implementação, forças de inovação e de manutenção costumam conflitar-se, em razão da coexistência de comunidades de fala em direções lingüísticas opostas. Na presença de tensão entre manutenção e conservação, variáveis estratificadas revelam-se eventualmente insuficientes para explicar direçóes de uma inovação. Uma análise mais detalhada da comunidade de fala deve, então, impor a exigência de outros indicadores sociolingüísticos e apontar a locação mais apropriada da variação e mudança lingüística. Nesse viés, encontram-se imbricadas algumas questôes. A predominância de uma variante lingüística estigmatizada acarreta necessariamente a predominância de outras variantes estigmatizadas? Dada a multiplicidade de perfis sociolingüísticos coexistentes, onde é possível traçar a fronteira entre grupos sociais?

Assim, paralelamente a questões estruturais, verifica-se o efeito de parâmetros de inscrição social sobre a variação e a mudança lingüística, com base em trabalhos comparativos que incluem diversos fenômenos variáveis, a maioria dos quais envolvendo a relação padrão/não padrão e estigmatizado/não estigmatizado (Santos, 1996). Os resultados indicam que a inclusão de parâmetros sociais, tal como proposto no modelo laboviano, propicia delineamento de perfil social do falante e de pressões a que está submetido, ao revelar sistematicidade e regularidade da atuação de aspectos extralingüísticos sobre a variação estável e a mudança em progresso. É possível até flagrar a existência de uma relação de implicação, determinada pelo valor social das variantes entre taxas de ocorrência da variação em um mesmo indivíduo: um falante que apresenta uma alta taxa de uma variante lingüística muito estigmatizada deverá apresentar também altas taxas de variantes estigmatizadas de um outro processo variável (Naro, 2001). 
Quanto a categorias e interpretaçóes, muitos estudos fundamentamse em princípios funcionalistas que preconizam, por exemplo, processos de gramaticalização para explicar mutações lingüísticas e estratégias compensatórias relacionadas à manutenção do equilíbrio dos sistemas (Martelotta et al. 1996; Furtado da Cunha, 2000). Ao considerar aspectos teóricodescritivos, tais como recategorização e ressemantização, as investigações recorrem a amostras diversas, em diferentes perspectivas, para compreender a complexidade da heterogeneidade lingüística.

Desse modo, a discussão de um modelo de mudança deve considerar também a atuação de princípios discursivo-funcionais, tais como unidirecionalidade, marcação, paralelismo e topicidade (Braga, 2001). Sob o enfoque funcionalista, atesta-se que o processo de gramaticalização é relevante para processos aquisitivos, podendo oferecer sustentação paradigmática, na medida em que se verifique emparelhamento entre o sincrônico e o diacrônico. A pesquisa sobre estágios aquisitivos de regras variáveis é importante para averiguar a maneira pela qual a criança equaciona o problema da forma-função e como o grau de transparência entre forma-função afeta a ordem da aquisição (Mollica \& Martellota, 2000). Constata-se, em alguns trabalhos, que o percurso aquisitivo, em geral, verifica-se na direção de uma codificação em que o desenvolvimento obedece a motivaçôes de ordem pragmática e lingüístico-cognitiva, estreitamente vinculadas a estágios aquisitivos.

Vale esclarecer que, ao localizar a variação e a mudança no indivíduo, alguns paradigmas teóricos partem de pressupostos diferentes. De um lado, acredita-se que os falantes e seus perfis sociolingüísticos reais ou desejados reforçam e/ou são responsáveis por inovaçôes. De outro, certos modelos formais costumam responsabilizar as crianças como agentes propulsores de inovaçōes, ao fazerem suas escolhas ao longo do processo de construção de suas gramáticas. De uma ótica mais propriamente gerativista, oferecese uma contribuição à construção de paradigma de mudança sob perspectiva diferenciada (Roberts \& Kato, 1993).

Há que se considerar, ainda, estudos que levam em conta a influência do grau de atenção que os falantes dispensam à produção lingüística. Entendam-se aí os correlatos discursivo-pragmáticos como contraparte para a dinâmica do sistema, seja no sentido da estabilidade, seja no sentido da mudança, como retração ou avanço. Incluem-se nesse enfoque os gêneros 
discursivos, os estilos conversacionais, as características dos atos de falam, a variação lingüística observada na escrita e na fala e a natureza simétrica ou assimétrica dos indivíduos envolvidos na interação face-a-face. Assim, aposta-se na interferência de fatores sócio-conversacionais sobre a mudança lingüística (Mollica \& Moita Lopes, 1994; Preti, 1998).

Discute-se, por último, a participação do léxico dentre as estratégias de implementação de inovações, ao defender-se a proposta da difusão lexical no âmbito de um modelo que pretende explicar a mudança lingüística (Oliveira, 1992). Advoga-se o princípio de que as regras são paulatinamente encaixadas e/ou fixadas na história e em processos de aquisição, espalhando-se pelo léxico, à medida que o repertório lingüístico vai sendo ampliado ontogênica e historicamente. É nesse sentido que as análises nessa linha se voltam para verificar o funcionamento real de leis concernentes a processos de gradualidade e de regularidade. Dado o conjunto de fenômenos examinados, interessa discutir o alcance explicativo dos dois modelos mais difundidos e debatidos: o da difusão lexical e o dos neogramáticos. Numa proposta para se observar a gênese da variação, admite-se que as regras, grosso modo, são categóricas no início ou tenuamente controladas; tornam-se variáveis e mais fortemente controladas ao longo do tempo, dependendo do grau de complexidade da gramática e da taxa de ocorrência de itens lexicais potencialmente afetáveis por um dado fenômeno em análise.

\section{Tendências anotadas}

Fica claro que não se podem descartar os princípios lexicais, funcionais, discursivo-pragmáticos e os inerentes aos sistemas. As técnicas de tempo aparente e tempo real complementam-se e os enfoques sincrônico e diacrônico evidenciam-se como indispensáveis. Os diferentes estudos dos pesquisadores da área demonstram que não é possível ignorar a variável tempo para um diagnóstico seguro acerca de mudanças lingüísticas. Comprovam, por outro lado, que a mudança pode ser entendida em sentido estrito, quando há de fato substituição de uma forma em relação à outra e, em sentido lato, quando há diferenças no grau de variabilidade e de contextualização de fenômenos variáveis. 
Constata-se, no conjunto dos estudos, uma pluralidade teóricometodológica nitidamente presente, demonstrando que: (a) as pesquisas sobre o uso da língua não podem restringir-se a dogmatismos teóricos; (b) a mudança lingüística tem de ser estudada sob diferentes enfoques, se se deseja uma compreensão mais aprofundada do dinamismo inerente às línguas; (c) o estudo em tempo real e em tempo aparente tem de resgatar a importância da atuação dos componentes social, estrutural, lexical e individual, responsáveis conjuntamente pela mudança; (d) considerando-se (b) e (c) como fundamentais, impõe-se a constituição e a utilização de inúmeros corpora, quer em falantes de L1 e L2 em aquisição, quer em gramáticas já consolidadas do português em estágios atuais e mais antigos do idioma.

A experiência dos pesquisadores em acessar database diferentes vem sendo consolidada entre os pares, concorrendo para disponibilizar novas amostras, com métodos tecnicamente apropriados, visando atingir resultados mais pontuais. Sendo assim, a área de pesquisa em Sociolingüística amplia-se e enriquece-se epistemologicamente. Se, por um lado, essa expansão é desejável, por outro, impõe restriçōes para a ciência, pois os avanços no campo ficam a depender de um conjunto de achados em diferentes direçôes que acabam por criar mais questôes do que respostas.

\section{Dimensão aplicada}

No nível aplicado, define-se como meta a transformação do conhecimento básico em material instrucional - softers educacionais, fitas magnéticas, vídeos, publicações - subsidiário para a formação de docentes e discentes de nível médio e superior. A transferência de produtos da investigação, veiculada em linguagem didático-pedagógica nas áreas de aprendizagem, produção de texto e leitura, constitui condição primordial para que o material de interface adquira relevância substantiva (Mollica, 2000; Brandão, 1996; Cardoso, 1996 e Cabral \& Gorski, 1998).

As descobertas da área podem ser divulgadas em $c d$-rom a professores de ensino fundamental e médio, abrangendo aspectos sobre usos e funcionamento da língua e processos de aquisição e mudança lingüística, traduzidos em linguagem adequada e com indicação de estratégias voltadas para o professor e para o aluno (Mollica, 2001, em preparo). 


\section{Agenda de trabalho}

É fato hoje que os estudiosos da área, em razão de sua contínua prática de pesquisa, desfrutam da oportunidade de examinar a mudança em tempo real com base em novos corpora, representativos do português hodierno e do português em seus primórdios (Callou \& Lopes, 1993; Mota e Rollemberg, 1994; Roncarati, 1996; Aragão \& Soares, 1996; Hilgert, 1997; Preti \& Hurbano, 1998; Furtado da Cunha, 1998; Paiva, 1999) Disponibilizado o patrimônio de database que recobre diversas áreas geodialetais no território brasileiro, torna-se possível estimular regular e sistematicamente uma produção comparativa a respeito de questôes teóricas de encaixamento e implementação da mudança e sua relação com a funcionalidade de estruturas variáveis; torna-se possível também conferir maior vitalidade à dimensão discursiva, viés característico dos sociolingüistas brasileiros. A interface entre variação, mudança e aquisição acha-se contemplada na pauta de trabalho.

As questôes de maior saliência que devem compor a agenda de trabalho voltam-se para: (a) exame da tensão entre fatores sociais e funcionais; (b) reflexão sobre a natureza da variação; (c) proposição de universais sociolingüísticos numa perspectiva comparativista inter e intralingüística; (d) aquisição da contraparte variável da língua em comunidades monolingües, bilingües e plurilíngües e (d) inter-relações entre variacionismo, geografia dialetal, funcionalismo e gerativismo.

É natural que se dê continuidade ao desenvolvimento de análises de fenômenos lingüísticos variáveis que possam favorecer a interação entre os grupos de pesquisa no Brasil, visando, de um lado, mapear a variação lingüística no território nacional e, de outro, participar da discussão teórica internacional sobre a relação entre variação e mudança lingüística, variação e mudança de código e variação inerente e gramáticas em competição.

Cumpre, por conseguinte, aprofundar a discussão na área sobre um modelo que possa abrigar motivações de natureza funcional e formal, assim como acolher a pesquisa sociolingüística interacional. Por último, resta ressaltar a coexistência da Sociolingüística stricto sensu com uma macroárea em que se incluem, por exemplo, a Crioulística, o Bilingüismo e o Multilingüismo, a Geolingüística e a Lingüística Histórica, dentre outros campos de investigação (Ferreira et. al. 1994; Aguilera, 1998). 
A Sociolingüística Aplicada vem-se incrementando em paralelo à interface teórica. Ao delinear procedimentos metodológicos, vem efetivamente legitimando os resultados provenientes da pesquisa básica e proporcionando a sua transferência para as áreas de educação (Mollica, 2000 e 2001), sem perder de vista a dialética inerente e esperada entre pesquisa pura e aplicada.

\section{REFERÊNCIAS Bibliográficas}

Aguilera, V. (1998) (org.) A Geolingüistica no Brasil: caminhos e perspectivas. Londrina: Ed. UEL.

Aragão, M. S. S. \& SoAres, M. E. (1996) (orgs.) A Linguagem Falada em Fortaleza - diálogos entre informantes e documentadores, materiais para estudo. Fortaleza: Universidade Federal do Ceará/ Centro de Humanidades/ Mestrado em Lingüística e Ensino da Língua Materna.

Braga, M. L. (2001) Princípios Atuantes no uso Lingüistico: tensão e sistematização. PEUL/UFRJ. Projeto aprovado pelo CNPq.

Bisol, L. (1991) (org.) A variação no português do Brasil. Organon 5 (18). Porto Alegre: UFRGS/ Instituto de Letras.

Bortoni, S. M. R. (1984) The Urbanization of Rural Dialect Speakers: a sociolinguistic study in Brazil. Cambridge: Cambridge University Press.

Brandão, S. (org.) Pesquisa \& Ensino da Lingua: contribuições da sociolingüística. UFRJ, Faculdade de Letras, Departamento de Vernáculas, 1996.

Cabral, L. G. \& Gorski, E. (1998) (orgs.) Lingüística e Ensino: reflexões para a prática pedagógica e da língua materna. Florianópolis: Insular.

Callou, D. Variação e Distribuição da Vibrante na Fala Urbana Culta do Rio de Janeiro. Tese de Doutorado, UFRJ, 1979.

et alii. (2000) (org.) Para uma História do Português Brasileiro: 500 anos de língua portuguesa no Brasil. PHPB- RJ/ FAPERJ. (Corpora em cd-rom).

\& Lopes, C. R. (1993) A Linguagem Falada Culta na Cidade do Rio de Janeiro - materiais para seu estudo. Rio de Janeiro: UFRJ/CAPES.

Cardoso, S. A. M. (1996) (org) Diversidade Lingüistica e Ensino. Salvador: EDUFBA. 
Couto, H. H. (1996) Introdução ao Estudo das Linguas Crioulas e Pidgins. Brasília: Editora Universidade de Brasília.

Couto, H. H. (org. e ed.) PAPIA - Revista de Crioulos de Base Ibérica, Universidade de Brasília.

Ferreira, C. et alii. (1994) Diversidade do Português, Estudos de Dialectologia Rural e Outros. Salvador: Centro Editorial e Didático da UFBA.

Furtado da Cunha, M. A. (1998) Corpus Discurso \& Gramática - a língua falada na cidade de Natal. Natal: EDUFRN.

(2000) (org.) Procedimentos Discursivos na Fala de Natal- uma abordagem funcionalista. Natal: Editora da EDUFRN.

Hilgert, J. G. (1997) (org.) A Linguagem Falada Culta na Cidade de Porto Alegre. Passo Fundo: Ediupf; Porto Alegre: Ed. Universidade/ UFGRS. Hora, D. de. (1997) Diversidade Lingüistica no Brasil. João Pessoa: Idéia. Hora, D. da. \& Christiano, E. (1999) (orgs.) Estudos Lingüisticos: realidade brasileira. João Pessoa: Idéia.

Labov, W. (1994) Principles of Linguistic Change: internal factors. Oxford UK \& Cambridge USA: Blackwell. (2000) Principles of Linguistic Change: external factors. Blackwell, Oxford UK, Cambridge USA.

Lemle, M. \& NARO, A. J. (1977) Competências Básicas do Português. Relatório Final apresentado às instituições Fundação Ford e Movimento Brasileiro de Alfabetização (Mobral). Ms.

Mattos e Silva, R. V. (1996) (org.) A Carta de Caminha: testemunho lingüístico de 1500. Salvador: Editora da UFBA.

MollicA, M.C. (1992) Introdução à Sociolingüistica Variacionista. Cadernos Didáticos/ UFRJ. (1995) (De) que Falamos? Rio de Janeiro: Tempo Brasileiro. (2000) Influência da Fala na Alfabetização. 2a ed. Rio de Janeiro: Tempo Brasileiro. (2001) Da Fala Coloquial à Escrita Padrão (em preparo). \& Moita Lopes (1994) Linguagem, interação e cognição. Revista Tempo Brasileiro 117, abr./jul.

\& MartelotTa, M.E. (2000) Análises Lingüísticas: a contribuição de Alzira Macedo. Rio de Janeiro: Universidade Federal do Rio de Janeiro/ Faculdade de Letras/ Departamento de Lingüística e Filologia. Macedo, A T. de; Roncarati, C. \& Mollica, M.C. (1996) (orgs.) Variação e Discurso. Rio de Janeiro: Tempo Brasileiro. 
Martelotta, M.; Votre, S. J. \& Cezario, M. M. (1996) Gramaticalização no Português do Brasil. Rio de Janeiro: Tempo Brasileiro.

Mota, J. \& Rollemberg, V. (1994) (orgs.) A Linguagem Falada Culta na Cidade de Salvador. Salvador: Universidade Federal da Bahia: Instituto de Letras.

Naro, J. A. (2001) Implementação e Encaixamento da Mudança Lingüistica. Relatório Final do Projeto PEUL/UFRJ, apresentado ao CNPq, em fevereiro.

Oliveira e Silva, G. M. \& Scherre, M. M. P. (1996) Padróes Sociolingüísticos: análise de fenômenos variáveis do português falado na cidade do Rio de Janeiro. Rio de Janeiro: Tempo Brasileiro.

Oliveira, Marco Antônio (1992) (org.) Revista de Estudos da Linguagem, 1(1). Faculdade de Letras da UFMG.

Paiva, M. C. de \& Scherre, M. M. P. (1999) Retrospectiva sociolingüística: contribuiçôes do PEUL. D.E. L.T.A., 15 Especial: 201-232.

Preti, D. (1998) Estudos de Lingua Falada: variações e confrontos. São Paulo: Humanitas/FFLCH/USP.

\& Urbano, H. (1998) (org.) A Linguagem Falada Culta na Cidade de São Paulo - materiais para seu estudo. São Paulo: T.A . Queiroz Ed. RELATÓRIO Final do Projeto PEUL III/UFRJ, apresentado ao CNPq em julho de 1997, sob a coordenação de Maria Cecília Mollica.

RELATÓRIO Final do Projeto PEUL III/UFRJ, apresentado ao CNPq em fevereiro de 1997, UFRJ, sob a coordenação de Maria Cecília Mollica.

Roberts, I. \& Kato, M. (1993) (orgs.) Português Brasileiro - uma viagem diacrônica: homenagem a Fernando Tarallo. Campinas: Unicamp.

Roncarati, C. (1996) Banco de Dados Interacionais. Rio de Janeiro: PósGraduação em Lingüística/ UFRJ/Faculdade de Letras/ CNPq.

Roncarati, C. \& Mollica, M. C. (1997) (orgs.) Variação e Aquisição. Rio de Janeiro: Tempo Brasileiro.

Paiva, M. da C. (1999) (org.) Amostras do Português Falado no Rio de Janeiro. Pós-Graduação em Lingüística/ Faculdade de Letras/CAPES.

SAntos, E. dos (1996) Certo ou Errado? Atitudes e crenças no ensino da língua portuguesa. Rio de Janeiro: Graphia.

Tarallo, F. (1989) (org. ) Fotografias Sociolingüísticas. Campinas, SP: Pontes: Editora da Universidade Estadual de Campinas.

\& Alkmin, T. (1987) Falares Crioulos: línguas em contato. São Paulo: Ática. 